\title{
Research on the classification for road traffic visibility based on the characteristics of driving behaviour - a driving simulator experiment
}

\author{
Kun Wang \\ College of Civil Engineering, Hefei University of Technology, Hefei, China \\ Weihua Zhang and Zhongxiang Feng \\ School of Automobile and Traffic Engineering, Hefei University of Technology, Hefei, China, and \\ Cheng Wang \\ College of Civil Engineering, Hefei University of Technology, Hefei, China
}

\begin{abstract}
Purpose - The purpose of this paper is to perform fine classification of road traffic visibility based on the characteristics of driving behavior under different visibility conditions.

Design/methodology/approach - A driving simulator experiment was conducted to collect data of speed and lane position. ANOVA was used to explore the difference in driving behavior under different visibility conditions.

Findings - The results show that only average speed is significantly different under different visibility conditions. With the visibility reducing, the average vehicle speed decreases. The road visibility conditions in a straight segment can be divided into five levels: less than 20, 20-30, 35-60, 60140 and more than $140 \mathrm{~m}$. The road visibility conditions in a curve segment can be also divided into four levels: less than 20, 20-30, 35-60 and more than $60 \mathrm{~m}$.

Originality/value - A fine classification of road traffic visibility has been performed, and these classifications help to establish more accurate control measures to ensure road traffic safety under low-visibility conditions.
\end{abstract}

Keywords Speed, Driving simulator experiment, Lane position, Low visibility, Traffic safety

Paper type Research paper

\section{Introduction}

Adverse weather conditions cause serious harm to road traffic safety, especially under low-visibility conditions related to fog. Previous studies have found that traffic accidents are more likely to happen under low-visibility conditions, and most of them are secondary accidents or multi-vehicle collisions under low-visibility conditions, which leads to more serious consequences (Abdel-Aty et al., 2011; Wang et al., 2017). The low-visibility conditions severely affect drivers' line of sight, which leads to a lack of accurate judgment of road geometry information and the real-time traffic flow state (Clark et al., 2004; Li et al., 2015). Statistics shows that approximately 600 fatalities and 16,300 injuries occur each year in fog-related crashes (US Department of Transportation, 2009). And the traffic safety situation under low-visibility conditions is also very serious in China. According to the China Road Accident Statistics Annual Report, 106,047 traffic accidents occurred in visibility lower than $200 \mathrm{~m}$ in China during 2015, leading to the deaths of 34,006 people, accounting for 58.61 per cent of all

The current issue and full text archive of this journal is available on Emerald Insight at: https://www.emerald.com/insight/2399-9802.htm

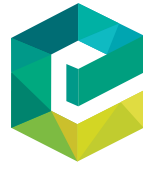

Journal of Intelligent and Connected Vehicles 3/1 (2020) 30-36

Emerald Publishing Limited [ISSN 2399-9802] [DOI 10.1108/JICV-10-2019-0011] traffic deaths (CRTASR, 2011). Facing the severe security situation, fine classification of road traffic visibility is of vital importance to establish more accurate control measures and to ensure road traffic safety under low-visibility condition.

The most obvious effect factor of low visibility on drivers' driving behavior is speed. Drivers will actively reduce driving speed to reduce risk when driving in fog (Yan et al., 2014; Hamdar et al., 2016). Wu et al. (2018) found significant differences in speed under different visibility conditions. Chen et al. (2013) proposed a nonlinear relationship between vehicle speed and visibility. Reduced visibility results in a trend of first increasing and then decreasing speed, and the maximum speed occurs when visibility is $80 \mathrm{~m}$. Brooks et al. (2011) found that drivers began to slow down when the visibility distance was

(C) Kun Wang, Weihua Zhang, Zhongxiang Feng and Cheng Wang. Published in Fournal of Intelligent and Connected Vehicles. Published by Emerald Publishing Limited. This article is published under the Creative Commons Attribution (CC BY 4.0) licence. Anyone may reproduce, distribute, translate and create derivative works of this article (for both commercial and non-commercial purposes), subject to full attribution to the original publication and authors. The full terms of this licence may be seen at http://creativecommons.org/licences/by/4.0/legalcode

This work was supported by the National Natural Science Foundation of China [grant No. 51878207, 51678211, 51578236, 71971073].

Received 22 October 2019

Revised 23 December 2019

Accepted 28 January 2020 
below $70 \mathrm{~m}$, but their speed was still high. Zhu et al. (2010) also found that within a certain range, the vehicle speed decreased about 15 per cent for every $50 \mathrm{~m}$ reduction in visibility.

In addition, the lane position characteristics are also used to explore the drivers' lateral driving behaviors. Zhao et al. (2015) used the drivers' speed control and lane position as observation variables to explore the influence of presence of a chevron alignment sign on the drivers' driving behavior at curve segment. Chen et al. (2013) and Brooks et al. (2011) explored drivers' lane-keeping ability under different visibility conditions. The results showed that drivers' lane-keeping ability will be significantly reduced when road visibility was less than $30 \mathrm{~m}$.

Although driving behaviors and control measures under different visibility conditions have been extensively studied, the classification of visibility conditions is mostly based on relevant standards and existing researches studies. And the lack of special research on visibility classification makes the implementation effect of control measures unable to achieve the optimal, thus resulting in the waste of road resources. Thus, we conducted a driving simulator experiment to explore the difference of speed control and lane position keeping under different visibility conditions at a straight segment and a curved segment. The road traffic visibility conditions will be graded finely. The findings from this approach have important scientific significance and practical value for ensuring road traffic safety and improving road operation efficiency.

\section{Method}

\subsection{Subjects}

This paper used 17 (visibility conditions) $\times 2$ (road segments) of the subject repeated measurement experimental design. A total of 25 postgraduates from Hefei University of Technology were recruited for this research. Each participant held a valid Chinese drivers' license and had at least two years' of driving experience. Out of the 25, 6 participants were excluded because of the presence of driving simulator sickness and 19 experimental participants were selected including 4 female drivers. The participants ranged from 21-28 years of age $($ mean $=24.2$, standard deviation $=1.9)$.

\subsection{Apparatus}

The driving simulation experiment can effectively avoid the safety risk of the driver driving in the really foggy environment. Driving simulator was used to load scenes with different visibility conditions, and drivers' driving behavior data under those conditions could be obtained. The Hefei University of
Technology's driving simulator was used to conduct the experiment and collect the data, as shown in Figure 1. The driving console was configured for a small car, including the complete instrument panel (speedometer, tachometer, indicator light), combination switch, steering switch, shift mechanism and user interface button, according to the actual car design on a 1:1 scale. The display system was composed of three 43-inch display screens at a resolution of $1,920 \times 1,080$ pixels, which provided a field of view of 150 horizontal degrees and 28 vertical degrees. The brake, accelerator and direction of the vehicle were designed based on the real-life situation, and the dashboard and rearview mirror displayed real-time vehicle speed information and surrounding visual traffic conditions. The simulator also provides the software (Scanner Studio 1.6) for driving scenario design, virtual traffic environment simulation and virtual road modeling. The simulator collected vehicle speed data at $100 \mathrm{~Hz}$ throughout all the experiments.

\subsection{Scenarios}

The scenario was simulated in a daytime environment, and the experimental scene included three simulated roads with the same line shape. Each simulated road had a four-lane secondary road with two lanes in each direction marked with single white edge lines and dual yellow centerlines. Each simulated road was about $8.4 \mathrm{~km}$ in length. The width of each lane was $3.75 \mathrm{~m}$, and the drivers must drive at a speed below the road design speed of $80 \mathrm{~km} / \mathrm{h}$. The visibility in this paper refers to the average distance at which the driver can observe the black large $\mathrm{E}$ mark in front. Recent studies on visibility and driving behavior have focused on visibility below $200 \mathrm{~m}$. When visibility is below $20 \mathrm{~m}$, drivers are unable to complete normal driving operations and this can interrupt driving (Hawkins, 1988; Brooks et al., 2011). Therefore, the visibility range of 20$200 \mathrm{~m}$ is taken as the research scope of this paper. The initial visibility of the scene can be divided into 17 levels, which can be further divided into three groups:

1 When the visibility condition is between 20 and $50 \mathrm{~m}$, the visual effect is loaded from the visibility of $20 \mathrm{~m}$ at intervals of $5 \mathrm{~m}$, that is, the visual effects are loaded with visibility of 20, 25, 30, 35, 40, 45 and $50 \mathrm{~m}$.

2 When the visibility condition is between 50 and $100 \mathrm{~m}$, the visual effect is loaded at intervals of $10 \mathrm{~m}$, that is, the visibility is $60,70,80,90$ and $100 \mathrm{~m}$.

3 When the visibility condition is between 100 and $200 \mathrm{~m}$, the visual effect is loaded at intervals of $20 \mathrm{~m}$, that is, the visibility is $120,140,160,180$ and $200 \mathrm{~m}$.

Figure 1 Driving simulator
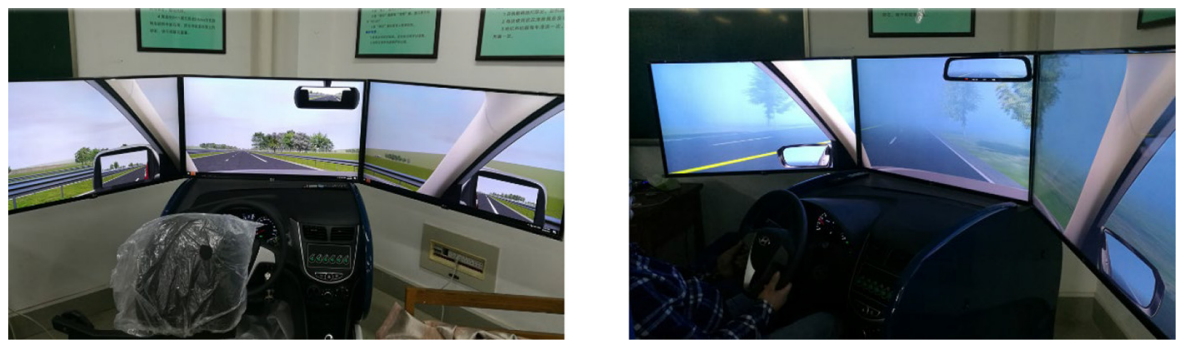
To obtain the driving behavior of the driver under different visibility conditions, each simulated road is divided into seven segments with different visibility conditions. Each main experimental segment has a length of $1 \mathrm{~km}$, consisting of a $500 \mathrm{~m}$ straight line and a $500 \mathrm{~m}$ curved road with a radius of $400 \mathrm{~m}$ (Figure 2). Considering the participants' adaptive driving process, each scenario was designed to begin with a straight segment of $1,000 \mathrm{~m}$. Each two experimental segments were separated by a straight transition segment with a length of $200 \mathrm{~m}$. An appropriate amount of opposite traffic flow is set in the scene, but there is no other vehicle interference in the experimental lane. At the same time, to avoid interference with experimental data by other factors, all roads are horizontal.

To avoid the test order effect, visibility conditions were selected randomly from initial visibility conditions for simulated roads as shown in Table I. At the same time, to avoid the fact that the real data cannot be obtained because of the small difference in visibility between adjacent roads, the visibility of the adjacent experimental segments is required to be randomly selected in different groups of initial visibility.

\subsection{Experimental design and procedure}

Before the start of the experiment, participants were first told that the experiment would be used only for scientific research and would cause no harm to society or the participants. If they have any discomfort during the experiment, they can immediately stop the experiment, and the experiment paid remuneration in accordance with the proportion of time. The driver was introduced to relevant information of the driving simulator, including accelerator, brake and gear. The driver then carried out 5-10 $\mathrm{min}$ of driving adaptive training, requiring the driver to speed up, slow down, turn and other driving operations. After the training, the driver got off the car and took some rest. The researchers asked whether there were symptoms of nausea or vertigo in the process of driving; they asked and recorded whether the subjects had diseases affecting their normal driving, whether they had consumed drugs,

\section{Figure 2 Experiment scenario}

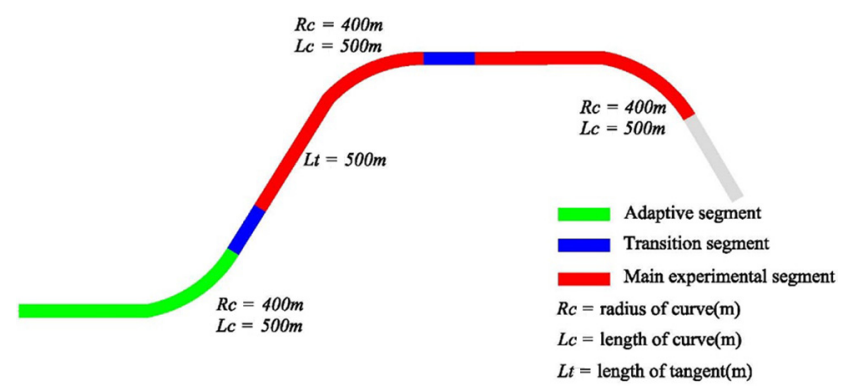

Table I Experimental group design

\begin{tabular}{lcccccc}
\hline & \multicolumn{6}{c}{ Visibility conditions (m) } \\
Simulated road group & $\mathbf{1}$ & $\mathbf{2}$ & $\mathbf{3}$ & $\mathbf{4}$ & $\mathbf{5}$ & $\mathbf{6}$ \\
\hline Group 1 & 20 & 60 & 140 & 40 & 70 & 120 \\
Group 2 & 80 & 25 & 160 & 100 & 35 & 180 \\
Group 3 & 30 & 90 & 45 & 200 & 50 & - \\
\hline
\end{tabular}

stimulated food or alcoholic beverages in the past two days, and they obtained all the basic information.

\subsubsection{Visibility correction experiment}

To avoid the deviation between the simulator visibility and the actual road visibility, the tester needs to correct the simulator visibility before conducting the visibility grading experiment. Based on Specifications for surface meteorological observation (GB/T 35237-2017) and the measurement method of static vision, a "E" sighting mark was chosen as the target object in this paper (National Standards of the People's Republic of China, 2017). The "C" sighting mark has a large hollow area, which was found not conform to the characteristics of the target object in preliminary experiment. According to the visibility research range of this paper corresponding to the size threshold of the target object, to make the target object adapt to different visibility sizes, $1.746 \mathrm{~m}$ was selected as the final side length of target object.

In the visibility calibration experiment, the initial visibility partition was set as the actual distance $x$ between the observation point and the target object " $E$ " in the scene. Then, the visibility on the driving simulator will start from 0 and increase one by one in $1 \mathrm{~m}$. When the subjects can distinguish the opening direction of target object " $E$ " accurately, the corresponding visibility $y$ in the simulator scene will be recorded. The above experiment was repeated until $x$ was equal to $200 \mathrm{~m}$.

\subsubsection{Visibility classification experiment}

For the main drive, the researchers told the participants to drive freely according to his/her usual driving habits in real-life situations and to stay in the initial lane and obey traffic laws and regulations. After completing the experiment, each participant was compensated $¥ 200$. Each participant was asked to sign an "experimental informed letter." The subjects were informed that they needed to drive three simulated scenarios in total, each of which is about $12 \mathrm{~min}$ long, and the rest time between each driving task is $3 \mathrm{~min}$.

\subsection{Statistical analysis}

The descriptive statistics were obtained to examine the sample size and frequencies of certain variables. ANOVA and least significant difference (LSD) multiple comparison test were used to explore the difference of driving behavior under different visibility conditions. The analyses were conducted using SPSS statistics software (version 19.0).

Figure 3 The fitting result of actual scene visibility and simulator visibility

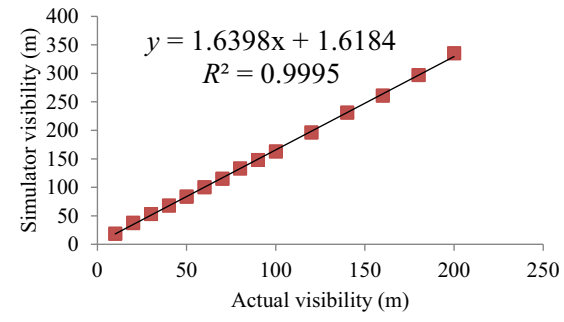




\section{Results}

\subsection{Visibility correction result}

The relationship between actual visibility and simulator visibility was fitted (Figure 3), and the correlation coefficient of the model was 0.9995. According to the fitting results, the simulator visibility corresponding to the initial visibility could be obtained (Table II), which can be used to correct the simulated visibility in subsequent experiments.

\subsection{Descriptive statistics}

The driving behavior characterizations studied in visibility classification experiment were speed and lane position. The variable of lane position referred to the distance between vehicle and road centerline. After the invalid data of speeding and run-out-of-road values was removed, the data of 19 test persons was used in the following analysis. Table III presents a summary of the average speed (SP_AVG), standard deviation of speed (SP_SD), average lane position (LP_AVG) and standard deviation of lane position (LP_SD) for each road segment. Table III shows that the average speed (SP_AVG) increased obviously with the increase of visibility conditions, but there were no obvious change trends for other variables.

\subsection{ANOVA analysis}

The variance's homogeneity should be tested before ANOVA, and the results showed that all of the SP_AVG, SP_SD, LP_AVG and LP_SD of straight segment and curved segment passed the variance homogeneity test $(p>0.05)$. The ANOVA results showed that only average speed of straight road and curved road have significant difference under different visibility conditions.

As visibility $(20 \mathrm{~m})$ was set as the reference category, we explored whether there were significant differences in average speed between the reference visibility condition and other visibility conditions (more than $20 \mathrm{~m}$ ) in order. Table IV shows that there is no significant differences in average speed between the reference visibility condition $(20 \mathrm{~m})$ and the next two visibility conditions $(25 \mathrm{~m}$ and $30 \mathrm{~m}$ ). But, the difference in average speed existed between the reference visibility condition $(20 \mathrm{~m})$ and visibility condition (more than $35 \mathrm{~m}$ ). The average speed of visibility condition (more than $35 \mathrm{~m}$ ) was significantly higher than that of reference visibility condition $(20 \mathrm{~m})$. At this time, the visibility condition $(35 \mathrm{~m})$ is defined as the visibility critical point, and the visibility $(35 \mathrm{~m})$ was used as the reference. The above analyses were repeated, and the other visibility critical points at straight segment were $60 \mathrm{~m}$ and $140 \mathrm{~m}$. Finally, the visibility conditions at straight segment have been divided into five

Table II The result of visibility correction

\begin{tabular}{lrrrrrr}
\hline Actual visibility (m) & 20 & 25 & 30 & 35 & 40 & 45 \\
Simulator visibility (m) & 34 & 43 & 51 & 59 & 67 & 75 \\
Actual visibility (m) & 50 & 60 & 70 & 80 & 90 & 100 \\
Simulator visibility (m) & 84 & 100 & 116 & 133 & 149 & 166 \\
Actual visibility (m) & 120 & 140 & 160 & 180 & 200 & - \\
Simulator visibility (m) & 198 & 231 & 264 & 297 & 330 & - \\
\hline
\end{tabular}

Table III Vehicle speed and lane position for each curve

\begin{tabular}{|c|c|c|c|c|c|}
\hline \multirow[b]{2}{*}{ Visibility } & \multirow[b]{2}{*}{ Road alignment } & \multicolumn{2}{|c|}{ Speed $(\mathrm{km} / \mathrm{h})$} & \multicolumn{2}{|c|}{ Lane position (m) } \\
\hline & & AVG & SD & AVG & SD \\
\hline \multirow[t]{2}{*}{20} & straight road & 36.424 & 4.711 & 1.898 & 0.141 \\
\hline & curved road & 35.147 & 3.701 & 1.846 & 0.165 \\
\hline \multirow[t]{2}{*}{25} & straight road & 37.334 & 5.517 & 1.943 & 0.195 \\
\hline & curved road & 36.559 & 4.157 & 1.895 & 0.183 \\
\hline \multirow[t]{2}{*}{30} & straight road & 37.126 & 3.589 & 1.870 & 0.193 \\
\hline & curved road & 42.614 & 4.744 & 1.887 & 0.186 \\
\hline \multirow[t]{2}{*}{35} & straight road & 44.429 & 3.551 & 1.867 & 0.154 \\
\hline & curved road & 39.034 & 4.087 & 1.929 & 0.219 \\
\hline \multirow[t]{2}{*}{40} & straight road & 42.450 & 4.803 & 1.924 & 0.178 \\
\hline & curved road & 43.198 & 4.055 & 1.963 & 0.202 \\
\hline \multirow[t]{2}{*}{45} & straight road & 43.092 & 3.568 & 1.899 & 0.205 \\
\hline & curved road & 43.840 & 4.275 & 1.903 & 0.230 \\
\hline \multirow[t]{2}{*}{50} & straight road & 45.044 & 3.752 & 1.851 & 0.175 \\
\hline & curved road & 43.796 & 3.887 & 1.936 & 0.210 \\
\hline \multirow[t]{2}{*}{60} & straight road & 52.882 & 3.247 & 1.919 & 0.177 \\
\hline & curved road & 51.995 & 3.683 & 1.822 & 0.181 \\
\hline \multirow[t]{2}{*}{70} & straight road & 54.507 & 3.967 & 1.804 & 0.163 \\
\hline & curved road & 51.185 & 4.528 & 1.977 & 0.220 \\
\hline \multirow[t]{2}{*}{80} & straight road & 54.354 & 2.518 & 1.885 & 0.146 \\
\hline & curved road & 54.686 & 3.497 & 1.936 & 0.182 \\
\hline \multirow[t]{2}{*}{90} & straight road & 54.808 & 4.279 & 1.930 & 0.161 \\
\hline & curved road & 54.019 & 3.782 & 1.880 & 0.197 \\
\hline \multirow[t]{2}{*}{100} & straight road & 57.158 & 3.555 & 1.935 & 0.172 \\
\hline & curved road & 52.006 & 3.691 & 2.055 & 0.209 \\
\hline \multirow[t]{2}{*}{120} & straight road & 57.043 & 3.534 & 1.785 & 0.160 \\
\hline & curved road & 53.419 & 4.347 & 2.022 & 0.220 \\
\hline \multirow[t]{2}{*}{140} & straight road & 64.495 & 3.255 & 1.937 & 0.156 \\
\hline & curved road & 56.937 & 3.955 & 1.939 & 0.193 \\
\hline \multirow[t]{2}{*}{160} & straight road & 61.865 & 4.247 & 1.986 & 0.179 \\
\hline & curved road & 56.046 & 4.194 & 2.018 & 0.203 \\
\hline \multirow[t]{2}{*}{180} & straight road & 63.753 & 4.628 & 1.842 & 0.154 \\
\hline & curved road & 57.579 & 4.826 & 1.964 & 0.194 \\
\hline \multirow[t]{2}{*}{200} & straight road & 67.632 & 3.786 & 1.871 & 0.155 \\
\hline & curved road & 54.850 & 4.993 & 1.991 & 0.203 \\
\hline
\end{tabular}

levels, which are less than 20, 20-30, 35-60, 60-140 and more than $140 \mathrm{~m}$.

The multiple comparisons of the effect of visibility conditions on average speed at curved segment have been analyzed similarly. Table V shows that the visibility conditions at curved segment have been divided into four levels which are less than 20, 20-30, 35-60 and more than $60 \mathrm{~m}$. Because of the limited space of the paper, Tables IV and V only show partial analysis results.

Figure 4 shows that the higher the visibility at straight sections, the greater the dispersion of SP_AVG, while the dispersion degree of SP_AVG at curved sections increased at first and then decreased. The broken lines in Figure 4 show the changes in SP_AVG at straight sections and curved sections under different visibility conditions. For straight and curved sections, the SP_AVG tended to increase with the increase of visibility. The graph of significance test showed a significant difference in SP_AVG between straight and curved sections under different visibility conditions. The results in the graph were consistent with the analysis results in Tables IV and V. 
Table IV Multiple comparisons of the effect of visibility conditions on average speed at straight segment

\begin{tabular}{|c|c|c|c|c|c|}
\hline \multirow[b]{2}{*}{ Visibility (I) } & \multirow[b]{2}{*}{ Visibility (J) } & \multirow[b]{2}{*}{ Mean difference (I-J) } & \multirow[b]{2}{*}{ Sig } & \multicolumn{2}{|c|}{$95 \%$ confidence interval } \\
\hline & & & & Lower & Upper \\
\hline \multirow[t]{3}{*}{20} & 25 & -0.910 & 0.787 & -7.524 & 5.704 \\
\hline & 30 & -0.702 & 0.835 & -7.316 & 5.912 \\
\hline & 35 & -8.005 & 0.018 & -14.620 & -1.391 \\
\hline \multirow[t]{4}{*}{35} & 40 & 1.979 & 0.556 & -4.635 & 8.594 \\
\hline & 45 & 1.338 & 0.687 & -5.181 & 7.857 \\
\hline & 50 & -0.615 & 0.853 & -7.134 & 5.904 \\
\hline & 60 & -8.453 & 0.012 & -15.067 & -1.838 \\
\hline \multirow[t]{6}{*}{60} & 70 & -1.624 & 0.634 & -8.333 & 5.084 \\
\hline & 80 & -1.472 & 0.666 & -8.180 & 5.236 \\
\hline & 90 & -1.926 & 0.567 & -8.540 & 4.689 \\
\hline & 100 & -4.276 & 0.204 & -10.891 & 2.338 \\
\hline & 120 & -4.161 & 0.223 & -10.869 & 2.548 \\
\hline & 140 & -11.613 & 0.001 & -18.321 & -4.905 \\
\hline \multirow[t]{3}{*}{140} & 160 & 2.631 & 0.441 & -4.077 & 9.339 \\
\hline & 180 & 0.742 & 0.828 & -5.966 & 7.450 \\
\hline & 200 & -3.136 & 0.358 & -9.844 & 3.572 \\
\hline
\end{tabular}

Table V Multiple comparisons of the effect of visibility conditions on average speed at curved segment

\begin{tabular}{|c|c|c|c|c|c|}
\hline \multirow{2}{*}{ Visibility (I) } & \multirow[b]{2}{*}{ Visibility (J) } & \multirow[b]{2}{*}{ Mean difference $(I-J)$} & \multirow[b]{2}{*}{ Sig. } & \multicolumn{2}{|c|}{ 95\% confidence interval } \\
\hline & & & & Lower & Upper \\
\hline \multirow[t]{3}{*}{$\overline{20}$} & 25 & -1.412 & 0.707 & -8.805 & $\overline{5.982}$ \\
\hline & 30 & -3.887 & 0.302 & -11.281 & 3.506 \\
\hline & 35 & -7.467 & 0.048 & -14.860 & -0.073 \\
\hline \multirow[t]{4}{*}{35} & 40 & -0.584 & 0.877 & -7.978 & 6.809 \\
\hline & 45 & -1.227 & 0.741 & -8.514 & 6.060 \\
\hline & 50 & -1.182 & 0.750 & -8.470 & 6.105 \\
\hline & 60 & -9.381 & 0.013 & -16.774 & -1.987 \\
\hline \multirow[t]{9}{*}{60} & 70 & 0.809 & 0.832 & -6.689 & 8.308 \\
\hline & 80 & -2.692 & 0.474 & -10.086 & 4.702 \\
\hline & 90 & -2.025 & 0.590 & -9.418 & 5.369 \\
\hline & 100 & -0.011 & 0.998 & -7.405 & 7.382 \\
\hline & 120 & -1.424 & 0.709 & -8.923 & 6.074 \\
\hline & 140 & -4.942 & 0.196 & -12.441 & 2.556 \\
\hline & 160 & -4.052 & 0.282 & -11.445 & 3.342 \\
\hline & 180 & -5.585 & 0.138 & -12.978 & 1.809 \\
\hline & 200 & -2.855 & 0.448 & -10.249 & 4.538 \\
\hline
\end{tabular}

\section{Discussion}

The results of ANOVA showed that there were significant differences in average speed among different visibility conditions at straight segment. Lower visibility led to a decrease in drivers' average speed, which is consistent with previous researches (Zhu, 2010; Yan et al., 2014). Poor visibility conditions reduced drivers' line of sight and ability to recognize objects, leading to more errors in the drivers' judgment of the external environment and increasing accident risk under lowvisibility conditions (Abdel-Aty et al., 2011; Zhang et al., 2017). In these cases, drivers usually took a compensatory reduction in speed to reduce accident risk (Hoogendoorn et al., 2011).

The result showed there was also significant differences in the average speed among different visibility conditions in curve segment. The average speed reduced significantly when the visibility decreases to a certain range in curve segment. In curve segments, the drivers' scope of vision is smaller than that at straight segment, making it more difficult for the driver to observe the road ahead and obtain information about traffic flow, especially in low-visibility conditions (Martens et al., 1997). Meanwhile, the stability of the vehicle controlled by drivers weakens, increasing the driving intensity and load and causing a decrease in speed. There had no significant difference in the average speed at curve segment while the visibility is greater than $60 \mathrm{~m}$. While road visibility is greater than $60 \mathrm{~m}$, the key factor to limit drivers' sight is curve radius rather than road visibility condition. In addition, the average speed of curve segment is lower than that of straight segment, and the gap of average speed between straight segment and curve segment becomes 
Figure 4 Average speed of different visibility conditions at straight section and curved section

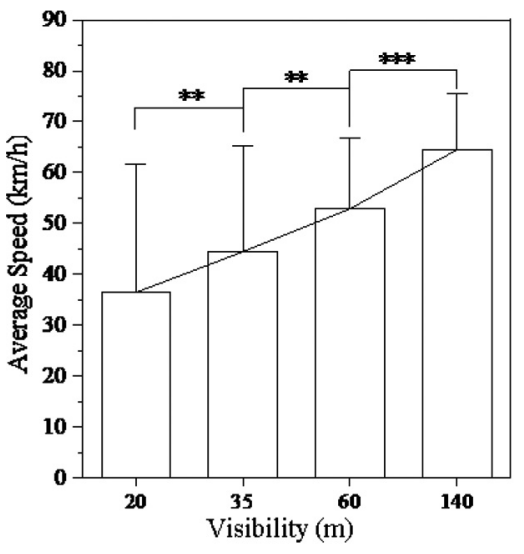

(a)

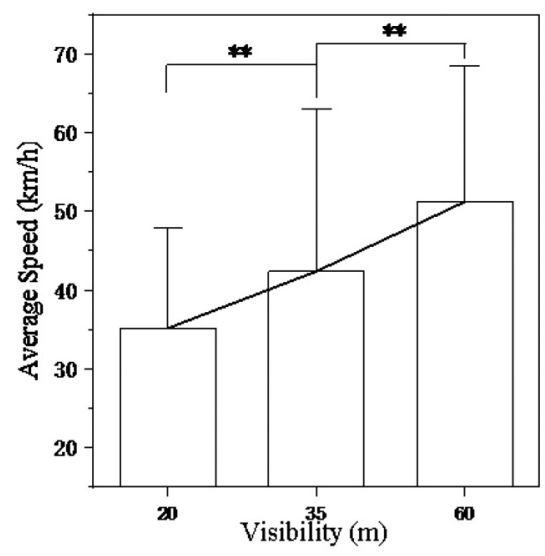

(b)

Notes: (a) Straight section; (b) curved section

larger and larger with the increase of visibility. Curve segment have a comparatively complex road geometry that makes driving risk significantly increased (Hummer et al., 2010). At this point, drivers tend to be more cautious and choose safer driving behaviors, especially for experienced drivers (Wallis and Horswill, 2007; Borowsky et al., 2009).

The present study also has some limitations. We only corrected the systematic errors of visibility in static conditions, and that in dynamic conditions such as different speeds need to be further improved. As road alignment parameters cannot be endlessly enumerated, subsequent research should select as many road alignment options as possible to further refine the conclusions of fine classification of road traffic visibility under different road alignment conditions. In addition to speed and lane position selected in this paper, other parameters such as physiological characteristics should be investigated. In addition, since the vehicle types have a significant impact on drivers' driving behavior, more vehicles with different types should be considered. The authors recommend that future studies may focus on these issues.

\section{Conclusion}

This study conducted a driving simulation experiment to explore the fine classification of road traffic visibility based on the characteristics of driving behavior under different visibility conditions. Specifically, the results obtained are as following:

- The average speed in on different road segments has significant difference under different visibility conditions.

- The visibility conditions at straight segment have been divided into five levels, which are less than 20, 20-30, 3560, 60-140 and more than $140 \mathrm{~m}$.

- The road visibility conditions at curved segment have been divided into four levels, which are less than 20, 2030, 35-60 and more than $60 \mathrm{~m}$.

These conclusions will help to establish more accurate control measures to ensure road traffic safety under low-visibility conditions.

\section{References}

Abdel-Aty, M., Ekram, A.A., Huang, H. and Choi, K. (2011), "A study on crashes related to visibility obstruction due to fog and smoke", Accident Analysis \& Prevention, Vol. 43 No. 5, pp. 1730-1737.

Borowsky, A., Oron-Gilad, T. and Parmet, Y. (2009), "Age and skill differences in classifying hazardous traffic scenes", Transportation Research Part F: Psychology and Behaviour, Vol. 12 No. 4, pp. 277-287.

Brooks, J.O., Crisler, M.C., Klein, N., Goodenough, R., Beeco, R.W., Guirl, C., Tyler, P.J., Hilpert, A., Miller, Y., Grygier, J. and Burroughs, B. (2011), "Speed choice and driving performance in simulated foggy conditions", Accident Analysis Eீ Prevention, Vol. 43 No. 3, pp. 698-705.

Chen, X.F., Qu, D.Y., Liu, Z.M. and Hao, J. (2013), “Driving performance research in foggy conditions based on driving simulator", Fournal of Wuhan University of Technology, Vol. 37 No. 4, pp. 763-766.

Clark, L., Tarek, S. and Francis, N. (2004), "A driver visual attention model: part 1: conceptual framework", Canadian Fournal of Civil Engineering, Vol. 31, pp. 463-472.

CRTASR (2011), “China Road Accidents Statistics Report in 2010", Traffic Administration Bureau of China, Beijing.

Hamdar, S., Qin, L. and Talebpour, A. (2016), "Weather and road geometry impact on longitudinal driving behavior: exploratory analysis using an empirically supported acceleration modeling framework", Transportation Research Part C: Emerging Technologies, Vol. 67, pp. 193-213.

Hawkins, R.K. (1988), "Motorway traffic behaviour in reduced visibility conditions", Second International Conference on Vision in Vehicles.

Hoogendoorn, R.G., Hoogendoorn, S.P., Brookhuis, K.A. and Daamen, W. (2011), "Adaptation Longitudinal Driving Behavior, Mental Workload, and Psycho-Spacing Models in Fog." Transportation Research Record, 2249, Transportation Research Board, Washington, DC, pp. 20-28.

Hummer, J.E., Rasdorf, W., Findley, D.J., Zegeer, C.V. and Sundstrom, C.A. (2010), "Curve crashes: road and collision 
characteristics and countermeasures", Fournal of Transportation Safety E Security, Vol. 2 No. 3, pp. 203-220.

Li, X., Yan, X. and Wong, S.C. (2015), "Effects of fog, driver experience and gender on driving behavior on S-curved road segments", Accident; Analysis and Prevention, Vol. 77, pp. 91-104.

Martens, M., Comte, S. and Kaptein, N. (1997), "The effects of road design on speed behaviour: a literature review", Video Systems, No. 5 .

National Standards of the People's Republic of China (2017), Specifications for surface Meteorological Observation (GB/T 35237-2017).

US Department of Transportation (2009), "How do weather events impact roads", Road Weather Management Program, available at: http://ops.fhwa.dot.gov/weather/q1 roadimpact. htm (accessed 13 May 2009).

Wallis, T.S.A. and Horswill, M.S. (2007), "Using fuzzy signal detection theory to determine why experienced and trained drivers respond faster than novices in a hazard perception test", Accident Analysis and Prevention, Vol. 39 No. 6, pp. 1177-1185.

Wang, Y., Liang, L. and Evans, L. (2017), "Fatal crashes involving large numbers of vehicles and weather", fournal of Safety Research, Vol. 63, pp. 1-7.
Wu, Y., Abdel-Aty, M. and Lee, J. (2018), “Crash risk analysis during fog conditions using real-time traffic data", Accident Analysis E Prevention, Vol. 114, pp. 4-11.

Yan, X., Li, X., Liu, Y. and Zhao, J. (2014), "Effects of foggy conditions on drivers' speed control behaviors at different risk levels", Safety Science, Vol. 68, pp. 275-287.

Zhang, W.H., Hu, Z., Feng, Z.X., Wang, K., Zhang, X.X. and Liu, X.F. (2017), "Analysis of factors influencing risky driving behaviors under reduced visibility condition", China Safety Science fournal, Vol. 27 No. 1, pp. 13-18.

Zhao, X.H., Wu, Y.P., Rong, J. and Ma, J. (2015), "The effect of chevron alignment signs on driver performance on horizontal curves with different roadway geometries", Accident Analysis \& Prevention, Vol. 75, pp. 226-235.

Zhu, Z.D., Rong, J. and Zhou, W. (2010), "Driver behaves in bad weathers", Fournal of Wuhan University of Technology, Vol. 34 No. 5, pp. 1040-1043.

\section{Corresponding author}

Zhongxiang Feng can be contacted at: fzx@hfut.edu.cn 